\title{
Statistical modeling of fatigue crack growth rate in pre-strained 7475-T7351 aluminum alloy
}

\author{
Kassim S. Al-Rubaie ${ }^{\text {a }}$, Emerson K.L. Barroso ${ }^{\mathrm{b}}$, Leonardo B. Godefroid ${ }^{\mathrm{c}, *}$ \\ a EMBRAER (Empresa Brasileira de Aeronáutica), Av. Brigadeiro Faria Lima 2170, \\ 12227-901 São José dos Campos, SP, Brazil \\ ${ }^{\mathrm{b}}$ CVRD (Companhia Vale do Rio Doce), Av. Dante Michelini, 5500, 29090-900 Vitória, ES, Brazil \\ ${ }^{\mathrm{c}}$ Universidade Federal de Ouro Preto, Escola de Minas, Deptartamento de Engenharia Metalúrgica e de Materiais, \\ Praça Tiradentes 20, 35400-000 Ouro Preto, MG, Brazil
}

Received 26 February 2007; received in revised form 16 September 2007; accepted 31 October 2007

\begin{abstract}
In this study, 7475-T7351 aluminum strips were subjected to two tensile pre-strain levels of 3\% and 5\%. Using compact tension C(T) specimens, fatigue crack growth tests were conducted under constant amplitude loading at stress ratios of 0.1 and 0.5 in air and at room temperature. Three fatigue crack growth rate (FCGR) models, namely, Collipriest, Priddle, and NASGRO were examined. To handle the effect of stress ratio on FCGR, Walker equivalent stress intensity factor model was used. Consequently, generalized Collipriest (GC), generalized Priddle (GP), and generalized NASGRO (GN) models were developed and fitted to the FCGR data. It was shown that both GC and GP models fit the FCGR data in a similar fashion. However, the GP model provided a better fit than the GC model. The GN model was found to be the most appropriate model for the data. Therefore, this model may be suggested for use in critical applications, such as aeronautical structural design.
\end{abstract}

(C) 2007 Elsevier B.V. All rights reserved.

Keywords: Modeling; Fatigue crack growth rate; Statistical analysis; 7475-T7351; Pre-strain

\section{Introduction}

High strength age-hardenable aluminum alloys, such as 2XXX and 7XXX, have been the most widely used structural materials in aeronautical industries due to their good mechanical properties and low densities [1-5].

The copper and magnesium bearing alloys $(2 \mathrm{XXX})$ are widely used for aircraft and space vehicles. The naturally aged and cold worked 2024-T3 is the most popular alloy of this group due to its good damage tolerance [1-4]. However, in the form of thick sheet, this alloy is susceptible to exfoliation corrosion $[1,6]$.

The zinc and magnesium bearing alloys (7XXX), of which 7075 is the most widely used, have the highest strengths by far. In the conventional peak-aged temper (T6), the thick plates, forgings, and extrusions of 7XXX series alloys are susceptible to stress corrosion cracking (SCC) [1,6-8]. The over-aged temper (T7) has been developed to improve the SCC resistance; how-

\footnotetext{
* Corresponding author. Tel.: +55 313551 3012/1586; fax: +55 1235513012

E-mail address: leonardo@demet.em.ufop.br (L.B. Godefroid).
}

ever, this results in loss of strength compared with the T6 temper $[9,10]$.

The need for high strength coupled with good fracture toughness and SCC resistance led to the development of the 7475 alloy [11]. This progress resulted from a considerable reduction in the levels of iron, silicon, and manganese, but also from improvements in thermo-mechanical and heat treatment practices [1,12].

In some cases, 7475-T7351 is being used after application of certain levels of pre-strain. Regarding the influence of prestraining on FCGR, few works [13-16] have been published. Hence, the objectives of this study are: (a) to show the effect of pre-strain on FCGR, and (b) to develop three generalized FCGR models and test them to determine which model provides the best-fit to the experimental data.

\section{Material and experimental procedure}

Aluminum alloy plate of 7475-T7351 with a thickness of $76.2 \mathrm{~mm}$ was used. The chemical composition is shown in Table 1. The alloy microstructure consists of a typical unrecrystallized pancake-like grain structure, as shown in Fig. 1. 
Table 1

Chemical composition of the 7475 aluminum alloy (wt.\%)

\begin{tabular}{|c|c|c|c|c|c|c|c|c|c|}
\hline Alloy & $\mathrm{Si}$ & $\mathrm{Fe}$ & $\mathrm{Cu}$ & $\mathrm{Mn}$ & $\mathrm{Mg}$ & $\mathrm{Zn}$ & $\mathrm{Cr}$ & $\mathrm{Ti}$ & $\mathrm{Al}$ \\
\hline 7475 & 0.029 & 0.085 & 1.661 & 0.01 & 2.376 & 5.722 & 0.21 & 0.0266 & Balance \\
\hline
\end{tabular}

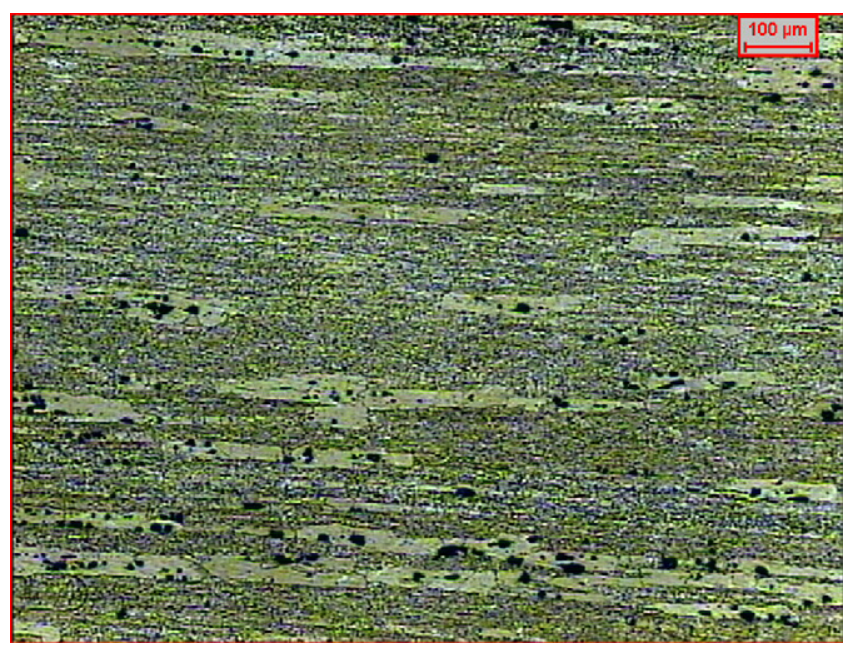

Fig. 1. Microstructure of 7475-T7351 alloy: A typical pancake-like grain structure is seen.

Strips of $5 \mathrm{~mm}$ thickness were machined from the original plate, and then subjected to two tensile pre-strain levels of $3 \%$ and 5\%. Further, in accordance with ASTM E8 [17], standard tensile test specimens were machined in the longitudinal direction. The $\mathrm{C}(\mathrm{T})$ specimens used for fracture toughness and for fatigue crack growth tests were machined in L-T direction, according to ASTM E647 [18]; the specimen dimensions are shown in Fig. 2.

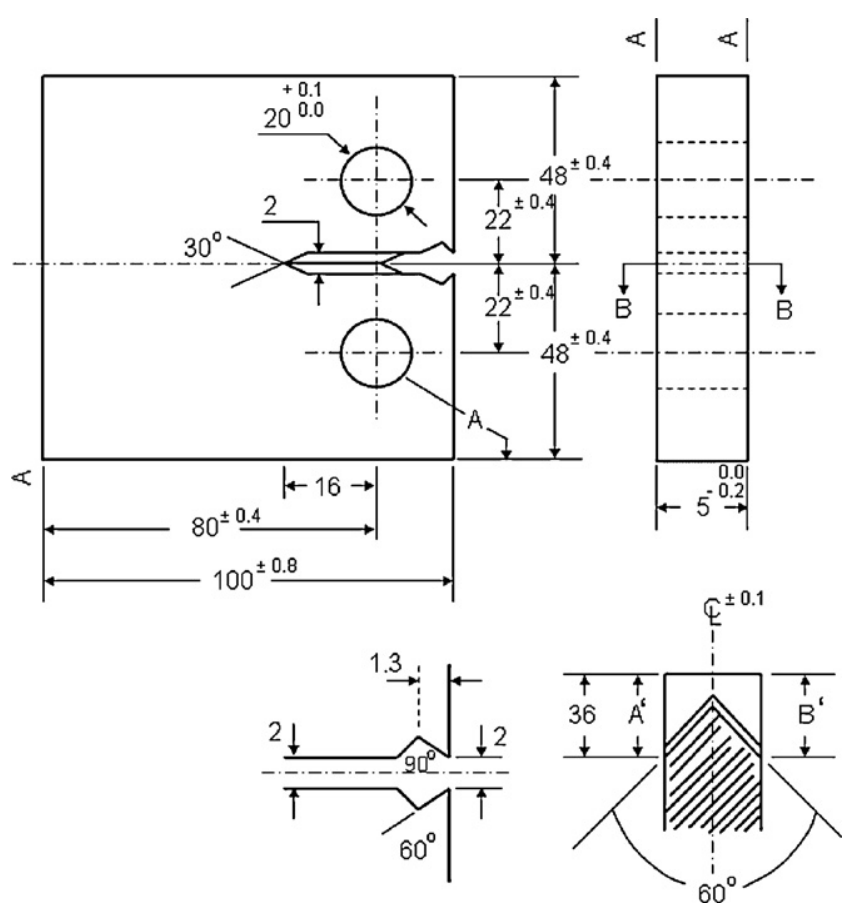

Fig. 2. Dimensional details of the $\mathrm{C}(\mathrm{T})$ specimen (dimensions in $\mathrm{mm}$ ).
Fatigue crack growth tests were conducted on pre-cracked C(T) specimens in accordance with ASTM E 647 [18]. The tests were done under a constant amplitude sinusoidal wave loading at stress ratios $(R)$ of 0.1 and 0.5 using a $100 \mathrm{kN}$ MTS servo-hydraulic machine, interfaced to a computer for machine control and data acquisition. The tests were conducted at a frequency of $30 \mathrm{~Hz}$ in air environment and at room temperature. The crack length was measured using a compliance method, in which a clip gauge is used to measure the elastic compliance of the specimen, which tends to increase with crack growth.

Moreover, fatigue crack growth threshold ( $\left.\Delta K_{\text {th }}\right)$ was evaluated using a constant $R$ load reduction "load shedding" method proposed in ASTM E647 [18]. In this method, both maximum and minimum loads applied to a cracked specimen are reduced such that $R$ ratio remains constant. Basically, the stress intensity factor range $(\Delta K)$ is gradually reduced until the FCGR reaches a very small value. According to ASTM E647, $\Delta K_{\text {th }}$ is about the $\Delta K$ corresponding to a FCGR $(\mathrm{d} a / \mathrm{d} N)$ of $10^{-10} \mathrm{~m} /$ cycle.

Fracture toughness was evaluated by the $K_{\mathrm{R}}$-curve determination at room temperature and in air environment, in the MTS servo-hydraulic testing machine using the $\mathrm{C}(\mathrm{T})$ specimens, in accordance to ASTM E561 [19]. The initial relative crack size, $a_{\mathrm{o}} / W=0.45$ was the same for all the specimens. Two tests were conducted for each pre-strain level. Basically, cyclic loading is applied to introduce a fatigue crack. When the crack reaches the desired length, the fatigue cycling is stopped and the load is gradually increased until fracture occurs. The stress intensity $K_{\mathrm{c}}$ is the value of $K_{\mathrm{R}}$ at the instability condition determined from the tangency point between the resistance $R$-curve and one of the applied $K$-curves.

Fracture surfaces were analyzed in a JEOL scanning electron microscope, model JSM 5510.

\section{Results and discussions}

\subsection{Tensile properties}

The results of tensile tests are presented in Table 2. Both $0.2 \%$ yield and ultimate tensile strength increase with an increase in the pre-strain level from $0 \%$ to $5 \%$. On the other hand, the total

Table 2

Average room temperature tensile test properties of 7475-T7351

\begin{tabular}{llllr}
\hline Pre-strain level & Orient. & $\sigma_{\mathrm{YS}}(\mathrm{MPa})$ & $\sigma_{\text {UTS }}(\mathrm{MPa})$ & $\varepsilon(\%)$ \\
\hline $0 \%$ & $\mathrm{~L}$ & 405.76 & 482.60 & 12.11 \\
$3 \%$ & $\mathrm{~L}$ & 412.17 & 496.38 & 9.82 \\
$5 \%$ & $\mathrm{~L}$ & 416 & 497.67 & 8.82 \\
\hline
\end{tabular}

$\sigma_{\text {YS }}: 0.2 \%$ yield tensile strength; $\sigma_{\mathrm{UTS}}$ : ultimate tensile strength; $\varepsilon$ : total strain. 
Table 3

Fracture toughness values of 7475-T7351

\begin{tabular}{ll}
\hline Pre-strain level & $K_{\mathrm{c}}(\mathrm{MPa} \sqrt{\mathrm{m}})$ \\
\hline $0 \%$ & 95.5 \\
$3 \%$ & 92.8 \\
$5 \%$ & 79.3 \\
\hline
\end{tabular}

strain to fracture decreases. These results are expected due to the effect of strain-hardening [20,21].

\subsection{Fracture toughness}

Table 3 shows the results of the fracture toughness $\left(K_{\mathrm{c}}\right)$ tests of 7475-T7351 for all cases of pre-strain studied.

The fracture toughness decreases with an increase in the pre-strain level [20-23]. A pre-straining of 5\% causes a reduction of $17 \%$ in $K_{\mathrm{c}}$. This is expected and is attributed to the effect of strain-hardening that leads to an increase in material strength. When the strength increases, the strain-hardening exponent decreases. This favors the formation and nucleation of microvoids with void sheet occurrence. This limits crack-tip opening displacement, thereby decreasing fracture toughness.

\subsection{FCGR modeling}

\subsubsection{FCGR models}

The reason for building models is to link theoretical ideas with the observed data to provide a good prediction of future observations. Modeling of FCGR data has enhanced the ability to create damage tolerant design philosophies.

Paris and Erdogan [24] proposed the most important and popular work. They observed a linear relationship between FCGR $(\mathrm{d} a / \mathrm{d} N)$ and $\Delta K$ when plotted on a $\log -\log$ scale. Paris and Erdogan proposed the power law relationship:

$\frac{\mathrm{d} a}{\mathrm{~d} N}=C \Delta K^{n}$

The Paris-Erdogan equation does not consider: (a) the effect of $R$, (b) the existence of $\Delta K_{\mathrm{th}}$, and (c) the accelerated FCGR when the maximum stress intensity factor $\left(K_{\max }\right)$ approaches the fracture toughness $\left(K_{\mathrm{c}}\right)$. It does not adequately describe FCGR regions I and III; it tends to overestimate region I and underestimate region III. Although the Paris-Erdogan equation is a simplification of a very complex phenomenon, it is still very popular on account of significant engineering interest.

The typical curve of a $\log (\mathrm{d} a / \mathrm{d} N)-\log (\Delta K)$, at a prescribed condition (environment and stress ratio), is sigmoidal in shape. It comprises three regions and is bounded at its extremes by $\Delta K_{\mathrm{th}}$ and $\Delta K_{\mathrm{c}}$. In the intermediate region of the curve, there is a linear relation between $\log (\mathrm{d} a / \mathrm{d} N)$ and $\log (\Delta K)$, as proposed by Paris and Erdogan.

Based on Eq. (1), several FCGR models have been suggested to fit all or part of the sigmoidal curve. In this study, three models that fit all parts of FCGR curve are considered. These models are:
1. Collipriest model

Collipriest proposed the following inverse hyperbolic tangent function $[25,26]$ :

$$
\begin{aligned}
\frac{\mathrm{d} a}{\mathrm{~d} N}= & C\left(K_{\mathrm{c}} \Delta K_{\mathrm{th}}\right)^{n / 2} \exp \left[\ln \left(\frac{K_{\mathrm{c}}}{\Delta K_{\mathrm{th}}}\right)^{n / 2}\right. \\
& \left.\times \tanh ^{-1} \frac{\ln \left(\Delta K^{2} /\left(\Delta K_{\mathrm{th}} K_{\mathrm{c}}(1-R)\right)\right)}{\ln \left(K_{\mathrm{c}}(1-R) / \Delta K_{\mathrm{th}}\right)}\right]
\end{aligned}
$$

where $\ln$ denotes the natural logarithm.

2. Priddle model

Priddle proposed the following function [27]:

$$
\frac{\mathrm{d} a}{\mathrm{~d} N}=C\left(\frac{\Delta K-\Delta K_{\mathrm{th}}}{K_{\mathrm{c}}-(\Delta K /(1-R))}\right)^{n}
$$

\section{NASGRO model}

Forman and Mettu [28] developed at NASA the following equation:

$$
\frac{\mathrm{d} a}{\mathrm{~d} N}=\frac{C \Delta K^{n}\left(1-\left(\Delta K_{\mathrm{th}} / \Delta K\right)\right)^{p}}{\left(1-\left(\Delta K / K_{\mathrm{c}}(1-R)\right)\right)^{q}}
$$

Eqs. (2)-(4) may be used only to fit one FCGR data set for a given $R$ ratio. If the data at hand are collected at $R=0.1$, the fitting models (2)-(4) cannot be used to estimate FCGR at another $R$, for example, at $R=0.5$.

To handle the effect of $R$ on FCGR, Walker [29] proposed the equivalent stress intensity factor model, which is widely accepted. It is given by:

$\Delta K_{\mathrm{eq}}=K_{\max }(1-R)^{m}$

$m$ is a Walker exponent and its objective is to control the spread of the FCGR curves for different values of $R ; \Delta K_{\mathrm{eq}}$ is an equivalent zero-to-tension $(R=0)$ stress intensity factor range. Knowing that $\Delta K=K_{\max }(1-R)$, then:

$$
\Delta K_{\mathrm{eq}}=\Delta K(1-R)^{m-1}
$$

In Eqs. (2)-(4), substituting $\Delta K$ with $\Delta K_{\text {eq }}$, putting $R=0$, and replacing $\Delta K_{\text {th }}$ by $K_{0}$, the generalized Collipriest (GC), generalized Priddle (GP), and generalized NASGRO (GN) models respectively may be written as:

$$
\begin{aligned}
\frac{\mathrm{d} a}{\mathrm{~d} N}= & C\left(K_{\mathrm{c}} K_{0}\right)^{n / 2} \exp \left[\ln \left(\frac{K_{\mathrm{c}}}{K_{0}}\right)^{n / 2}\right. \\
& \left.\times \tanh ^{-1}\left(\frac{\ln \left(\Delta K^{2}(1-R)^{2 m-2} / K_{0} K_{\mathrm{c}}\right)}{\ln \left(K_{\mathrm{c}} / K_{0}\right)}\right)\right]
\end{aligned}
$$

$\frac{\mathrm{d} a}{\mathrm{~d} N}=C\left(\frac{\Delta K(1-R)^{m-1}-K_{0}}{K_{\mathrm{c}}-\Delta K(1-R)^{m-1}}\right)^{n}$

$\frac{\mathrm{d} a}{\mathrm{~d} N}=\frac{C\left(\Delta K(1-R)^{m-1}\right)^{n}\left(1-\left(K_{0} /\left(\Delta K(1-R)^{m-1}\right)\right)\right)^{p}}{\left(1-\left(\Delta K(1-R)^{m-1} / K_{\mathrm{c}}\right)\right)^{q}}$

$C, n, m, p, q$, model parameters estimated from experimental data; $K_{0}$, threshold value at $R=0$. 
Table 4a

Estimated parameters of FCGR models, 7475-T7351, 0\% pre-strain

\begin{tabular}{llllrlll}
\hline Model & Parameter & Estimate & S.E. & $t$-Value & $p$-Value & $95 \%$ LCL & $95 \%$ UCL \\
\hline Generalized Collipriest (GC) & $C$ & $2.637 \mathrm{E}-10$ & $3.648 \mathrm{E}-11$ & 7.227 & $<0.0001$ & $1.918 \mathrm{E}-10$ & $3.355 \mathrm{E}-10$ \\
& $n$ & 2.312 & $5.272 \mathrm{E}-02$ & 43.861 & $<0.0001$ & 2.208 \\
& $m$ & 0.252 & $3.544 \mathrm{E}-02$ & 7.097 & $<0.0001$ & 0.182 \\
Generalized Priddle (GP) & $C$ & $4.490 \mathrm{E}-06$ & $4.647 \mathrm{E}-07$ & 9.663 & $<0.0001$ & $3.575 \mathrm{E}-06$ & 0.321 \\
& $n$ & 1.871 & $3.679 \mathrm{E}-02$ & 50.849 & $<0.0001$ & 1.798 \\
& $m$ & 0.280 & $3.212 \mathrm{E}-02$ & 8.721 & $<0.0001$ & 0.217 \\
Generalized NASGRO (GN) & $C$ & $5.496 \mathrm{E}-11$ & $4.132 \mathrm{E}-12$ & 13.300 & $<0.0001$ & $4.682 \mathrm{E}-11$ \\
& $n$ & 3.016 & $3.076 \mathrm{E}-02$ & 98.066 & $<0.0001$ & 2.956 \\
& $m$ & 0.459 & $2.145 \mathrm{E}-02$ & 21.410 & $<0.0001$ & 0.417 \\
\hline
\end{tabular}

Table $4 \mathrm{~b}$

Statistical properties of FCGR models, 7475-T7351, 0\% pre-strain

\begin{tabular}{lllllr}
\hline Model & SSE & S.E. & MSE & $F$ & $R^{2}$ \\
\hline Generalized Collipriest (GC) & 25.0316 & 0.3189 & 0.1018 & 1253.9 & 0.9107 \\
General Priddle (GP) & 19.7155 & 0.2831 & 0.0801 & 1625.2 & 0.9296 \\
General NASGRO (GN) & 5.8494 & 0.1542 & 0.0238 & 5769.4 & 0.9791 \\
\hline
\end{tabular}

Table 5a

Estimated parameters of FCGR models, 7475-T7351, 3\% pre-strain

\begin{tabular}{|c|c|c|c|c|c|c|c|}
\hline Model & Parameter & Estimate & S.E. & $t$-Value & $p$-Value & $95 \% \mathrm{LCL}$ & $95 \% \mathrm{UCL}$ \\
\hline \multirow[t]{3}{*}{ Generalized Collipriest (GC) } & $C$ & $2.727 \mathrm{E}-10$ & $2.147 \mathrm{E}-11$ & 12.704 & $<0.0001$ & $2.306 \mathrm{E}-10$ & $3.149 \mathrm{E}-10$ \\
\hline & $n$ & 2.499 & $2.908 \mathrm{E}-02$ & 85.966 & $<0.0001$ & 2.443 & 2.557 \\
\hline & $m$ & 0.473 & $2.276 \mathrm{E}-02$ & 20.772 & $<0.0001$ & 0.428 & 0.517 \\
\hline \multirow[t]{3}{*}{ Generalized Priddle (GP) } & $C$ & $9.368 \mathrm{E}-06$ & $5.276 \mathrm{E}-07$ & 17.755 & $<0.0001$ & $8.331 \mathrm{E}-06$ & $1.040 \mathrm{E}-05$ \\
\hline & $n$ & 2.037 & $2.004 \mathrm{E}-02$ & 101.588 & $<0.0001$ & 1.997 & 2.076 \\
\hline & $m$ & 0.502 & $2.001 \mathrm{E}-02$ & 25.086 & $<0.0001$ & 0.463 & 0.541 \\
\hline & $m$ & 0.582 & $1.423 \mathrm{E}-02$ & 40.933 & $<0.0001$ & 0.554 & 0.611 \\
\hline
\end{tabular}

The influence of $R$ on $\Delta K_{\text {th }}$ can be described by the most popular empirical equation proposed by Klesnil and Lukáš [30]:

$\Delta K_{\mathrm{th}, R}=\Delta K_{\mathrm{th}, 0}(1-R)^{\gamma}$

where $\Delta K_{\mathrm{th}, R}$ is the threshold stress intensity factor range for a given $R, \Delta K_{\mathrm{th}, 0}$ is the threshold value for $R=0$, which equals $K_{0}$, and the $\gamma$ value is between 0 and 1 . The objective of Eq. (10) is to estimate $K_{0}$ being used as a fixed parameter in the generalized fitting models.

In Eqs. (7)-(9), $R$ is an independent variable; it implies that two or more FCGR data sets collected at different $R$ ratios can be joined for the statistical analysis. Hence, the generalized fitting models (7)-(9) may be used to interpolate FCGR for $R$ ratios that were not considered in the testing program, thereby reducing both time and cost.

\subsubsection{Model fitting}

Eqs. (2)-(4) and (7)-(9) are nonlinear regression models. A nonlinear model has at least one parameter (quantity to be estimated) that appears nonlinearly [31]. Nonlinear regression is an iterative procedure, and the basis used for estimating the unknown parameters is the criterion of leastsquares. The fitting was carried out using a routine based on the Marquardt-Levenberg algorithm [32]. The fitting procedure provides (i) parameters, (ii) error estimate on the

Table $5 b$

Statistical properties of FCGR models, 7475-T7351, 3\% pre-strain

\begin{tabular}{llllll}
\hline Model & SSE & S.E. & MSE & $F$ & $R^{2}$ \\
\hline Generalized Collipriest (GC) & 28.7749 & 0.2431 & 0.0591 & 3997.9 & 0.9426 \\
General Priddle (GP) & 21.4729 & 0.2099 & 0.0441 & 5440.3 & 0.9572 \\
General NASGRO (GN) & 8.6857 & 0.1335 & 0.0178 & 13808 & 0.9424 \\
\hline
\end{tabular}


Table $6 \mathrm{a}$

Estimated parameters of FCGR models, 7475-T7351, 5\% pre-strain

\begin{tabular}{|c|c|c|c|c|c|c|c|}
\hline Model & Parameter & Estimate & S.E. & $t$-Value & $p$-Value & $95 \% \mathrm{LCL}$ & $95 \% \mathrm{UCL}$ \\
\hline \multirow[t]{3}{*}{ Generalized Collipriest (GC) } & $C$ & $3.956 \mathrm{E}-10$ & $5.173 \mathrm{E}-11$ & 7.647 & $<0.0001$ & $2.936 \mathrm{E}-10$ & $4.976 \mathrm{E}-10$ \\
\hline & $n$ & 2.308 & $4.761 \mathrm{E}-02$ & 48.467 & $<0.0001$ & 2.214 & 2.402 \\
\hline & $m$ & 0.388 & $5.601 \mathrm{E}-02$ & 6.936 & $<0.0001$ & 0.278 & 0.499 \\
\hline \multirow[t]{3}{*}{ Generalized Priddle (GP) } & $C$ & $4.240 \mathrm{E}-06$ & $4.407 \mathrm{E}-07$ & 9.621 & $<0.0001$ & $3.371 \mathrm{E}-06$ & $5.109 \mathrm{E}-06$ \\
\hline & $n$ & 1.884 & $3.393 \mathrm{E}-02$ & 55.538 & $<0.0001$ & 1.817 & 1.951 \\
\hline & $m$ & 0.424 & $4.953 \mathrm{E}-02$ & 8.565 & $<0.0001$ & 0.327 & 0.522 \\
\hline \multirow[t]{3}{*}{ Generalized NASGRO (GN) } & $C$ & $8.879 \mathrm{E}-11$ & $7.049 \mathrm{E}-12$ & 12.597 & $<0.0001$ & $7.490 \mathrm{E}-11$ & $1.027 \mathrm{E}-10$ \\
\hline & $n$ & 2.905 & $3.437 \mathrm{E}-02$ & 84.528 & $<0.0001$ & 2.837 & 2.973 \\
\hline & $m$ & 0.475 & $3.051 \mathrm{E}-02$ & 15.557 & $<0.0001$ & 0.415 & 0.535 \\
\hline
\end{tabular}

Table $6 b$

Statistical properties of FCGR models, 7475-T7351, 5\% pre-strain

\begin{tabular}{lllllr}
\hline Model & SSE & S.E. & MSE & $F$ & $R^{2}$ \\
\hline Generalized Collipriest (GC) & 20.9811 & 0.3161 & 0.0999 & 1196.1 & 0.9193 \\
General Priddle (GP) & 16.4431 & 0.2798 & 0.0783 & 1555.2 & 0.9367 \\
General NASGRO (GN) & 6.2933 & 0.1731 & 0.0299 & 4232.7 & 0.9758 \\
\hline
\end{tabular}

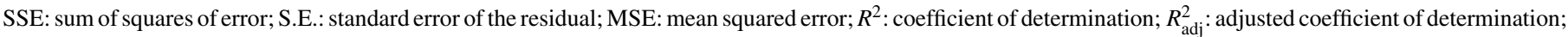
LCL: lower confidence limit; UCL: upper confidence limit.

parameter, and (iii) a statistical measure of goodness of fit.

The least-squares criterion quantifies goodness of fit as the sum of squares of the vertical distances of the data points from the assumed model. That is, the best model for a particular data set is that with the smallest sum of squares. In fact, it is not simple to compare models with different parameters. The problem is that a more complicated model (more parameters) gives more flexibility (more inflection points) for the curve being generated than the curve being defined by a simpler model (fewer parameters). Thereby, the sum of squares of a more complicated model tends to be lower.

To show the effect of $R$ on FCGR, Eqs. (7)-(9) were used for the nonlinear regression analysis. Both GC and GP models use three parameters $(C, n, m)$, while the GN model contains five parameters $(C, n, m, p, q)$. The objective of $p$ and $q$ is to provide a better fit to data in near-threshold and accelerated regions, respectively. The parameters $p$ and $q$ may be fixed, reducing the model parameters to three. For metallic materials, since the values of $p$ and $q$ are between 0 and 1, they were chosen by trial and error to be 0.20 and 0.80 , respectively. Finally, $C, n$, and $m$ of the selected models may be estimated using a nonlinear regression analysis.

The estimated parameters and the statistical properties for FCGR models are presented in Tables 4-6. The experimental data and the estimated curves are shown in Figs. 3-5.

For the cases of $0 \%, 3 \%$, and 5\% pre-strain, a visual examination of the fitting curves reveals that the GC and GP models fit the FCGR data in a similar fashion; however, the latter fits relatively better than the former. The GN model offers the best approximation of the data (Figs. 3-5).

From Tables $4 a-6 a$, at the 0.05 level of significance, it may be concluded that the estimated parameters $(C, n, m)$ are statistically

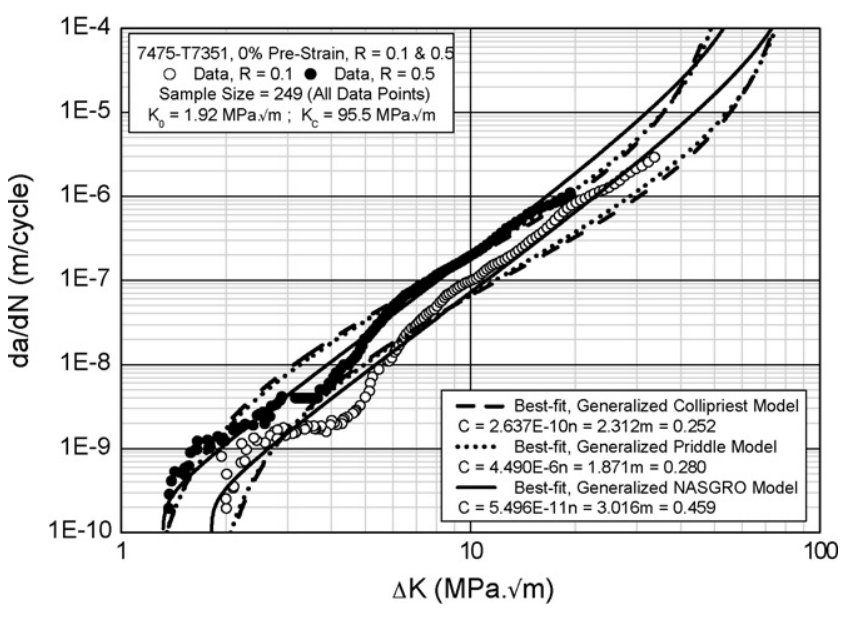

Fig. 3. FCGR comparative curves of $7475-\mathrm{T} 7351,0 \%$ pre-strain.

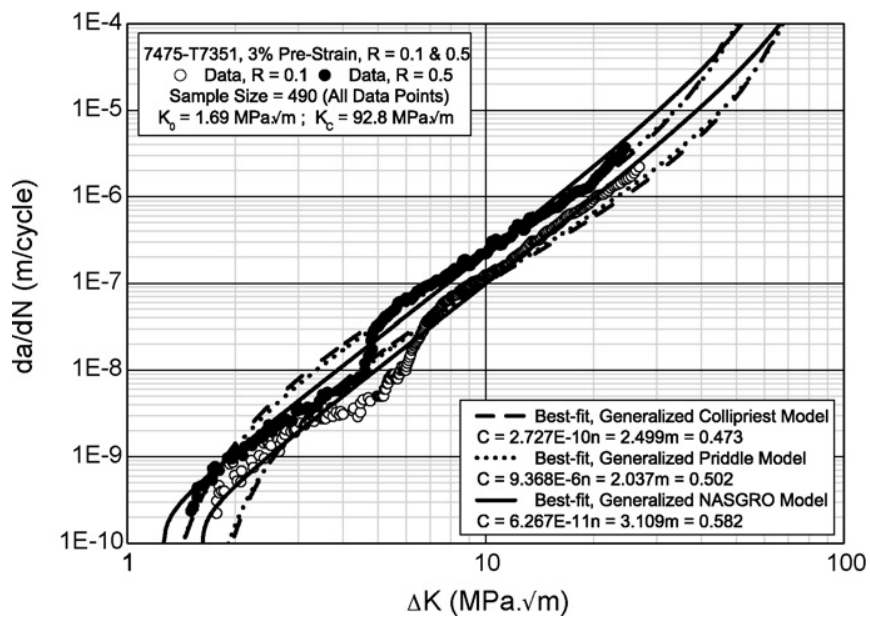

Fig. 4. FCGR comparative curves of $7475-\mathrm{T} 7351,3 \%$ pre-strain. 


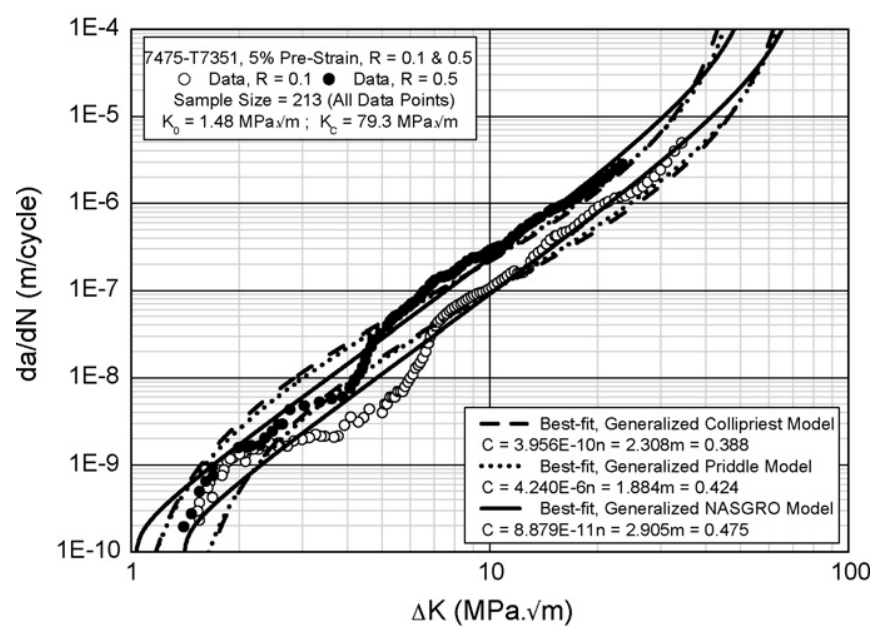

Fig. 5. FCGR comparative curves of 7475-T7351, 5\% pre-strain.

significant, since their $p$-values are smaller than the level of significance. The estimated parameters of the GN model are the most significant parameters. This may be confirmed by an examination of the $t$-value of the estimate. The $t$-value is the ratio of the estimate to its standard error, the latter being used to compute confidence band of the estimate.

Generally, a high $t$-value indicates that the estimate is well determined in the model and the confidence band will be narrow.
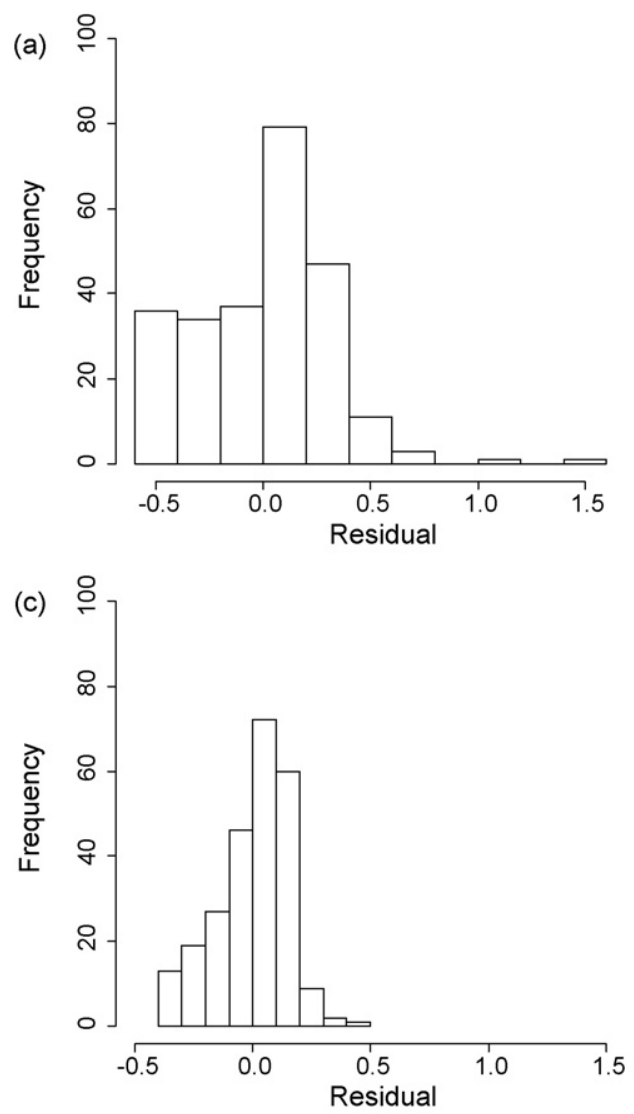

Conversely, a low $t$-value indicates that the estimate is poorly determined and the confidence band will be wide. An indication of high or low $t$-value of an estimate depends on the related $p$-value (probability) and significance level used. For a given significance level, an estimate is statistically significant when its $t$-value is high enough to provide a $p$-value less than the selected level of significance.

\subsubsection{Model validation}

There are many graphical and numerical tools to assist goodness of fit of a model used with experimental data [33,34]. The most common approach is to examine the residual.

The histogram plots presented in Figs. 6-8 suggest that the residuals (measured - predicted) of the GN model appear to be normally distributed. This desirable result indicates that the GN model is satisfactory.

Figs. 6d-8d illustrate side-by-side box plots of the residual data of the FCGR models. For the case of $0 \%$ pre-strain, at the 0.05 level of significance, using Kruskal-Wallis one way analysis of variance on ranks [34], no a statistically significant difference was found in the median values of residuals for the FCGR models. The same is true for $3 \%$ and $5 \%$ pre-strain cases. However, the variability in the residual data obtained from the GC model appears much greater than that from the GP model. In addition, outliers (extreme values) as indicated by the (o) symbols were detected. Due to the small range of the whiskers
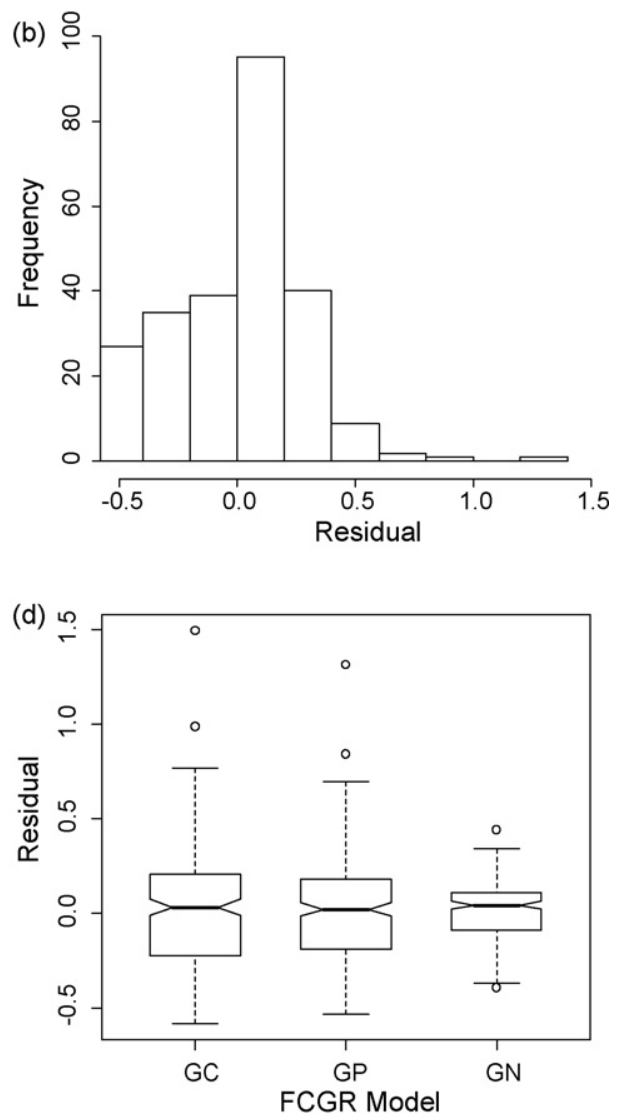

Fig. 6. Residual data of FCGR models, 7475-T7351, 0\% pre-strain; (a) generalized Collipriest model (GC), (b) generalized Priddle model (GP), (c) generalized NASGRO model (GN), and (d) box plot. 

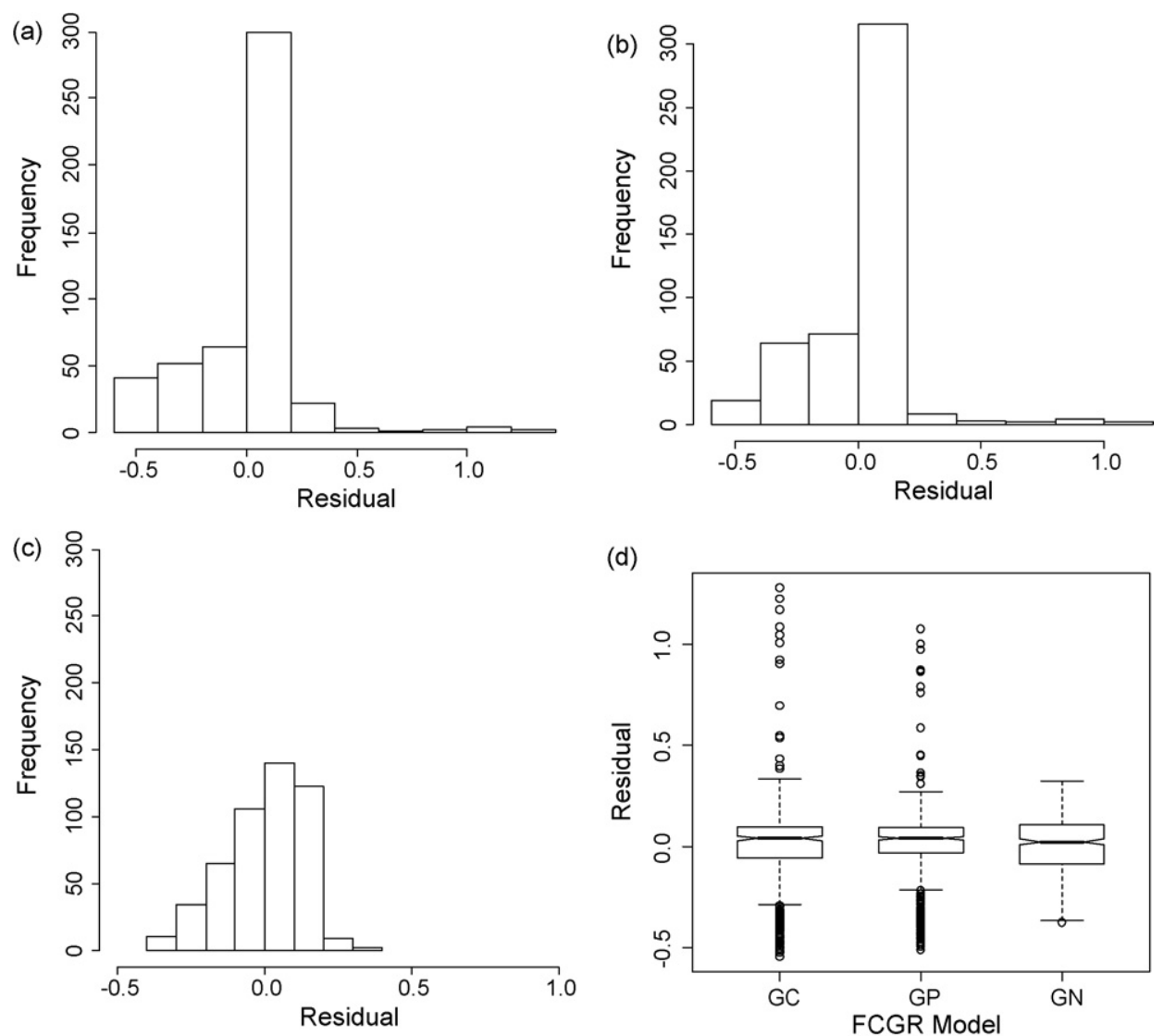

Fig. 7. Residual data of FCGR models, 7475-T7351, 3\% pre-strain; (a) generalized Collipriest model (GC), (b) generalized Priddle model (GP), (c) generalized NASGRO model (GN), and (d) box plot.

and length of the box, it may be concluded that the GN model is the most approximating model to the data.

To assess the model goodness of fit, several statistical numerical measures may be checked such as $R^{2}, R_{\text {adj }}^{2}, F$, S.E., MSE, Schwarz's Bayesian Information Criterion (BIC), and Akaike's Information Criterion (AIC) [35,36]. The $R^{2}$ statistic is a poor measure for model validation because adding an extra variable to a model will always increase $R^{2}$ even if the variable is completely unrelated to the response variable. The $R_{\text {adj }}^{2}$ statistic adjusts $R^{2}$ for the number of parameters in model. A model that maximizes $R_{\text {adj }}^{2}$ may be chosen. Large value of $F$, small values of S.E. and MSE indicate that the model explains the data well. Tables $4 \mathrm{~b}-6 \mathrm{~b}$ suggest that the GP model provides a better fit than the GC. On the other hand, the GN model seems to be the best approximating model to the data.

\subsection{Effect of $R$ ratio and pre-strain on FCGR}

The GN model provides a better fit to the FCGR data when compared with the other two models. Hence, it is used to illustrate the effects of pre-strain and $R$ ratio. Generally, Figs. 9 and 10 show that pre-straining relatively causes an increase in FCGR in the threshold region. However, an increase in pre-strain level has no appreciable influence in the Paris region, since this region is less sensitive to microstructural alterations as a result of the prestrain applied. In the unstable region, an increase in pre-strain from $0 \%$ to $5 \%$ causes a reduction of $17 \%$ in material fracture toughness (Table 3 ) and consequently alters the FCGR.

Table 7 shows the results of the threshold stress intensity factor range $\left(\Delta K_{\text {th }}\right)$ tests of 7475-T7351 for all cases of prestrain studied. At the same pre-strain condition, $\Delta K_{\text {th }}$ decreases with increasing the $R$ ratio; for $0 \%$ pre-strain, a reduction of $28 \%$ in $\Delta K_{\text {th }}$ is observed with increasing the $R$ ratio from 0.1 to 0.5 . At $R=0.1, \Delta K_{\text {th }}$ decreases with an increase in pre-strain level; a pre-straining of $5 \%$ causes a reduction of $19 \%$ in $\Delta K_{\text {th }}$. However, at $R=0.5$, a clear relation was not found; the average of the threshold values for pre-straining conditions was determined as $1.38 \mathrm{MPa} \sqrt{\mathrm{m}}$ with a coefficient of variation of 0.07 .

Several researchers have reported the influence of $R$ ratio on near-threshold FCGR in many alloy systems [37-49]. It has been shown that the phenomenon of crack closure plays an important role in near-threshold crack growth. At low stress intensities, crack opening displacements (COD) are relatively small. Thus,

Table 7

Fatigue threshold values of 7475-T7351

\begin{tabular}{lll}
\hline Pre-strain level & $\Delta K_{\mathrm{th}}(\mathrm{MPa} \sqrt{\mathrm{m}})$ & \\
\cline { 2 - 3 } & $R=0.1$ & $R=0.5$ \\
\hline $0 \%$ & 1.81 & 1.31 \\
$3 \%$ & 1.65 & 1.45 \\
$5 \%$ & 1.46 & 1.37 \\
\hline
\end{tabular}



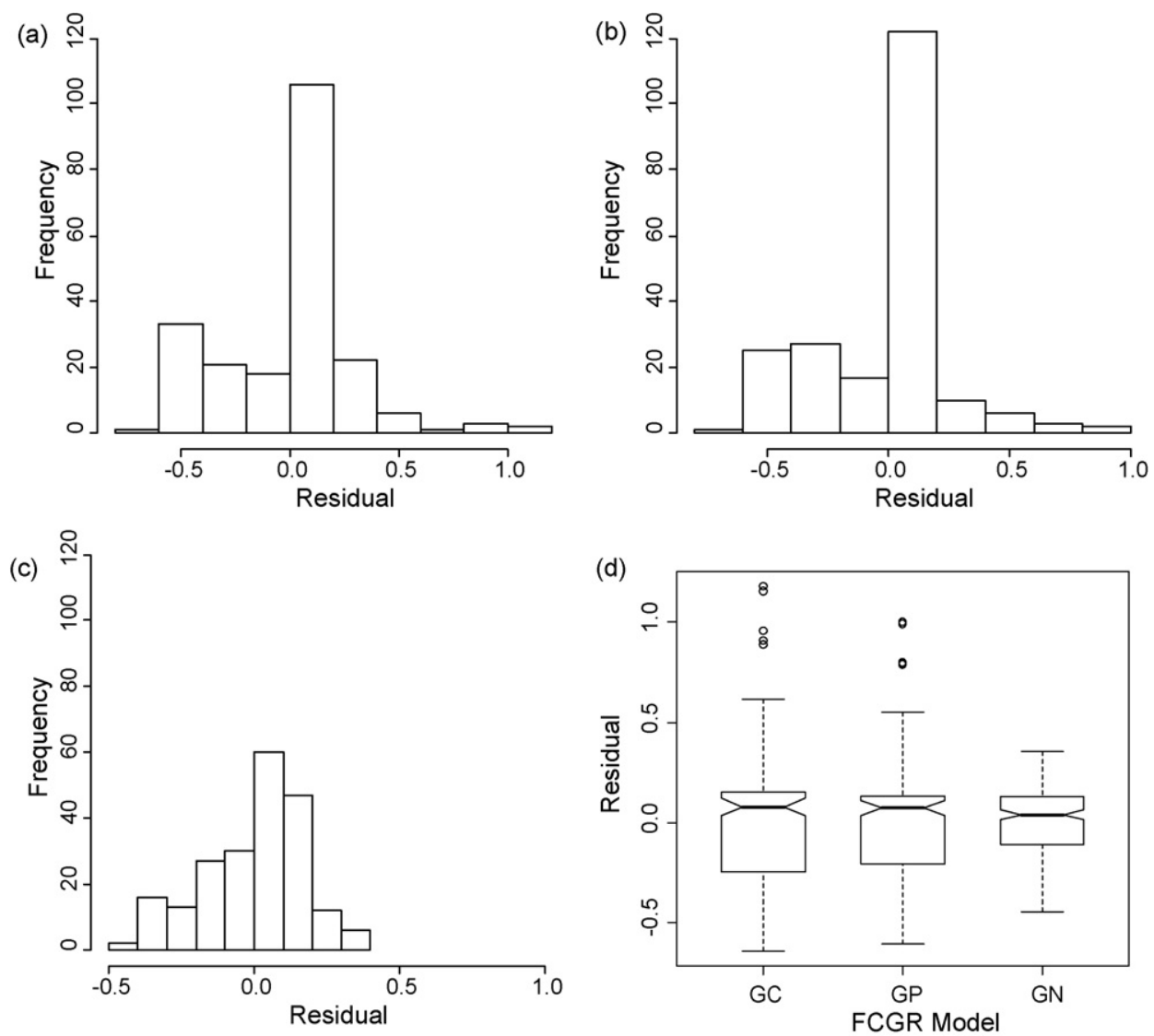

Fig. 8. Residual data of FCGR models, 7475-T7351, 5\% pre-strain; (a) generalized Collipriest model (GC), (b) generalized Priddle model (GP), (c) generalized NASGRO model (GN), and (d) box plot.

any oxide debris or microstructural feature (roughness) with a size comparable to the COD will promote early contact of the crack surfaces and result in crack closure. Moreover, the mode II displacements characteristic of near-threshold crack growth behavior enhances roughness-induced crack closure and accelerates the formation of oxide debris. Consequently, any factor that contributes to minimize the premature contact between the mating crack faces (for example: high $R$ ratio) also contributes to decrease $\Delta K_{\mathrm{th}}$.

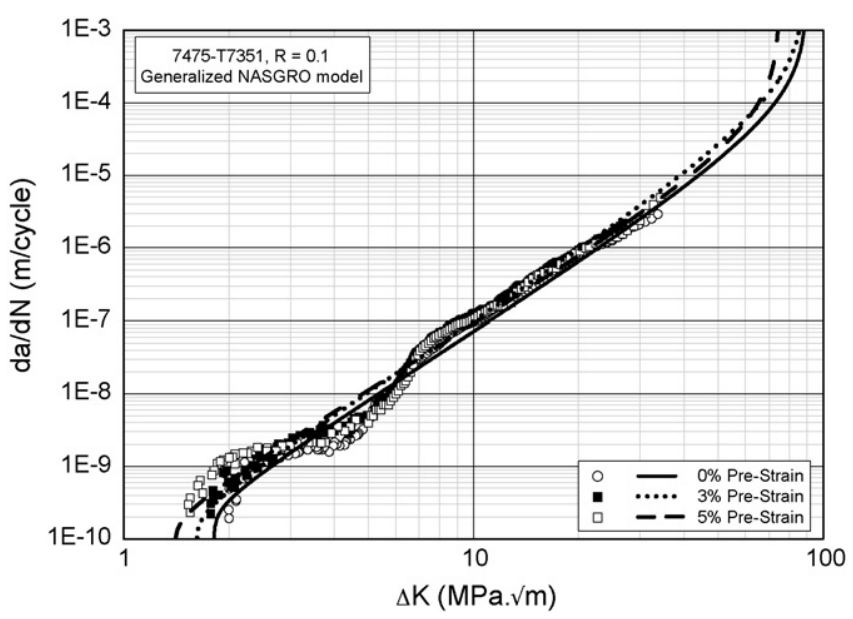

Fig. 9. Effect of pre-strain on the FCGR in 7475-T7351, $R=0.1$, GN model.
Different models have been proposed to explain the effect of pre-strain on near-threshold FCGR. One dislocation-based model [15] assumes that $\Delta K_{\mathrm{th}}$ is determined by the critical stress at the crack tip necessary to operate the nearest dislocation source. The effect of pre-straining is then considered to be due to a decrease of the distance between the crack tip and the nearest active dislocation source. Other dislocation-based model [15] assumes that the crack growth process is a repetition of microcrack nucleation within the slip bands at the crack

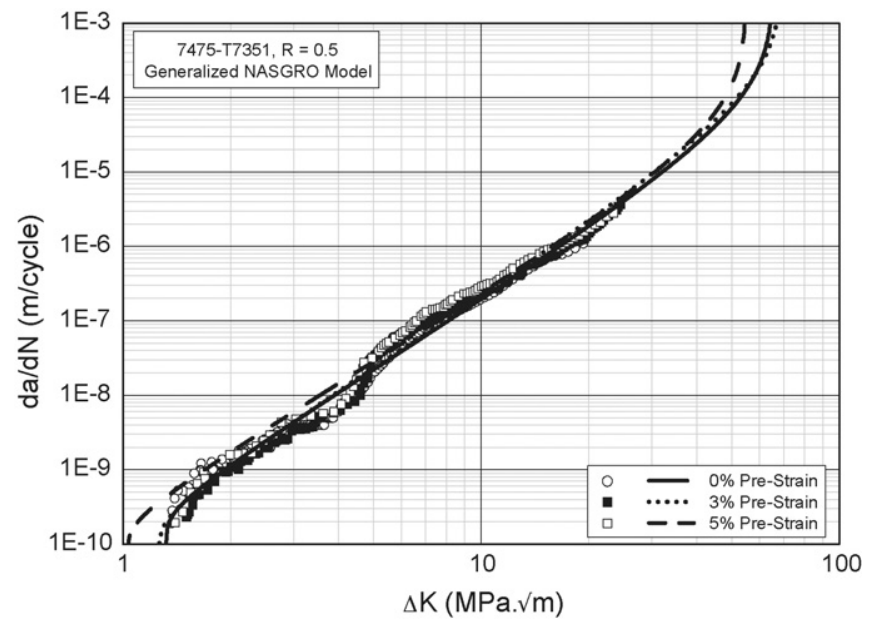

Fig. 10. Effect of pre-strain on the FCGR in 7475-T7351, $R=0.5$, GN model. 
tip caused by accumulated fatigue damage. The initially higher dislocation density in the pre-strained materials would intensify the plastic activity in the plastic zone, speeding up the accumulation of fatigue damage in the slip bands. As a result, the internal resistance towards crack advance should diminish and a decrease in $\Delta K_{\text {th }}$ should therefore occur.

Crack closure can also be used to explain the effect of prestrain on near-threshold FCGR [50-53]. In this case, the crack closure values of pre-strained materials go down as compared to the corresponding non pre-strained materials. These behaviors might be explained mainly by the change of the surface roughness of fatigue fractures. On the other hand, since crack closure is negligible at high values of $R, \Delta K_{\text {th }}$ is less affected by pre-strain level at higher values of $R$.

\subsection{Fractography}

At near-threshold level and at $R=0.1$, the scanning electron microscope (SEM) micrographs of fatigue fracture surfaces for the specimen without pre-strain (Fig. 11) revealed a flat, faceted appearance that resembles cleavage. The crack apparently follows specific crystallographic planes, and changes directions when it encounters a barrier such as a grain boundary.
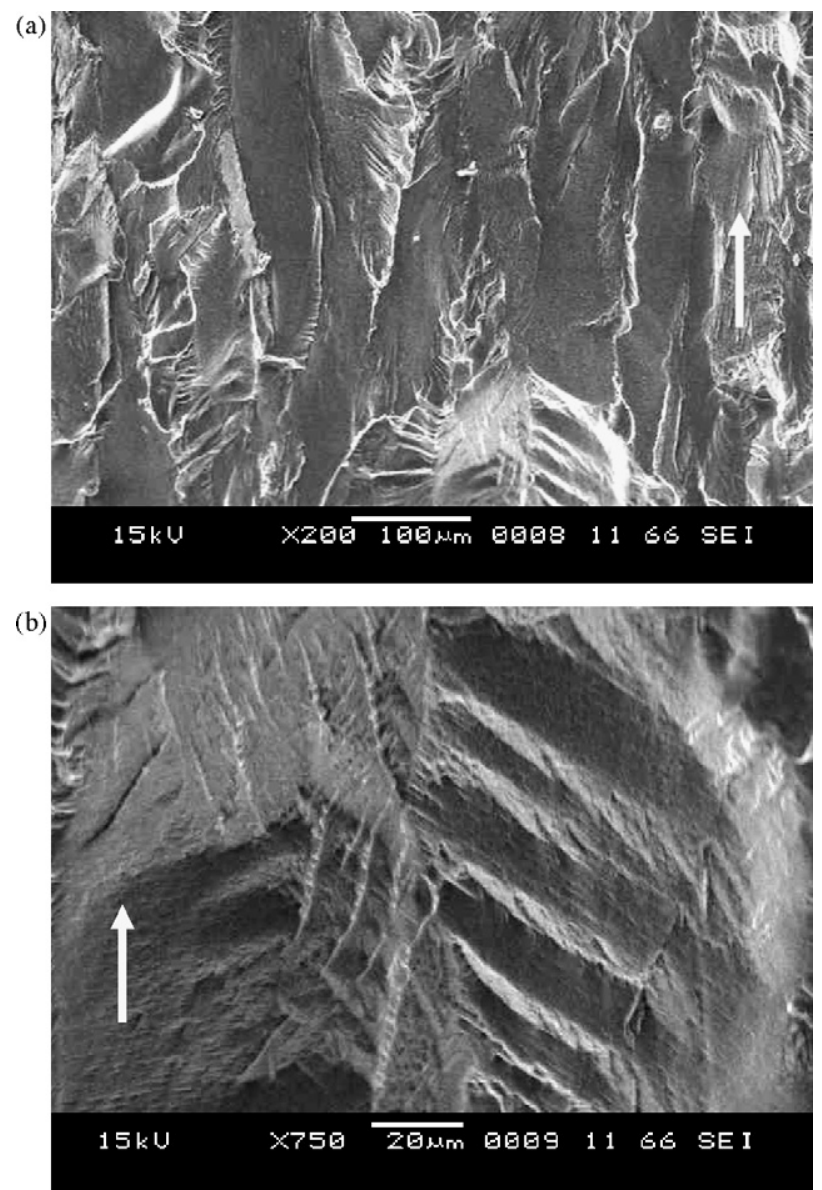

Fig. 11. SEM micrographs of the fracture surfaces at the near-threshold level, $7475-\mathrm{T} 7351, R=0.1,0 \%$ pre-strain, (a) $200 \times$, and (b) $750 \times$. Arrow indicates the direction of crack propagation.
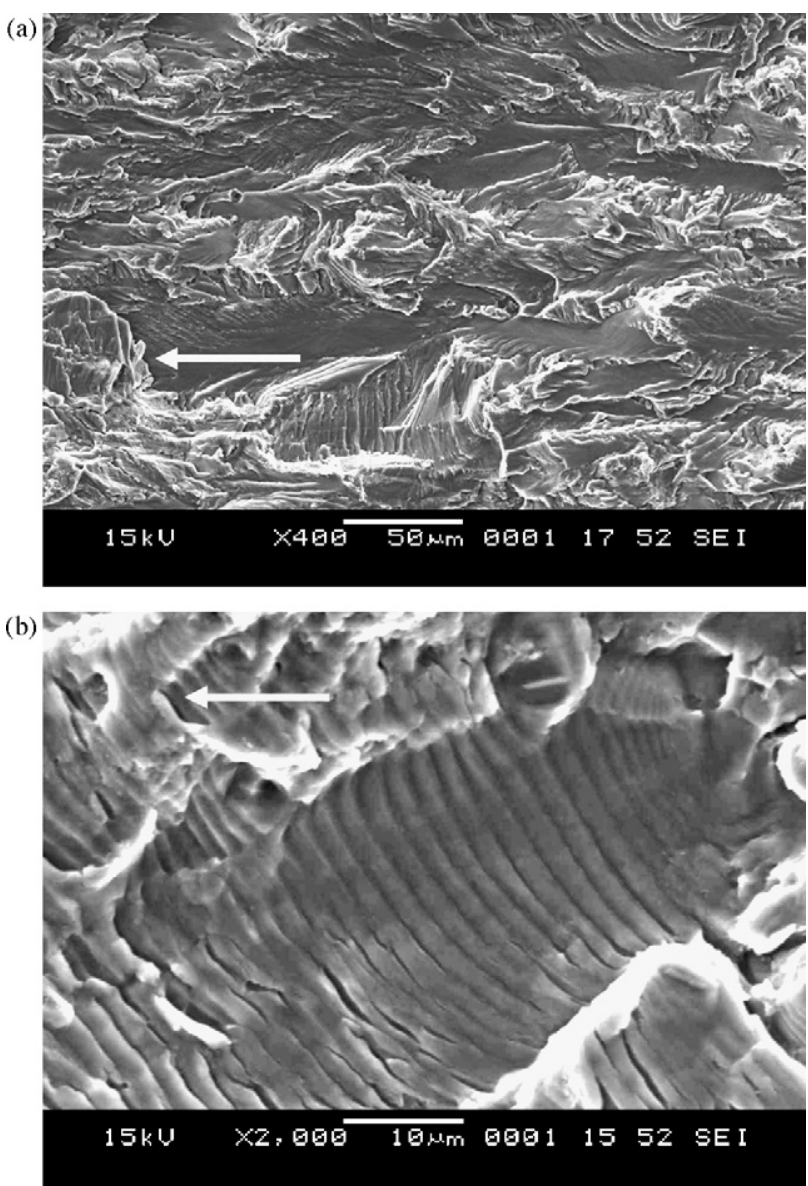

Fig. 12. SEM micrographs of the fracture surfaces in the linear FCGR region, $7475-\mathrm{T} 7351, R=0.1,0 \%$ pre-strain, (a) $400 \times$, and (b) $2000 \times$. Arrow indicates the direction of crack propagation.

This mechanism confirms the operation of the phenomenon of roughness-induced closure in this particular region. On the other hand, in the higher $\Delta K$ region, the fracture surface was distinctly smoother than at near-threshold level, and ductile striations were the dominant features (Fig. 12). These two different mechanisms

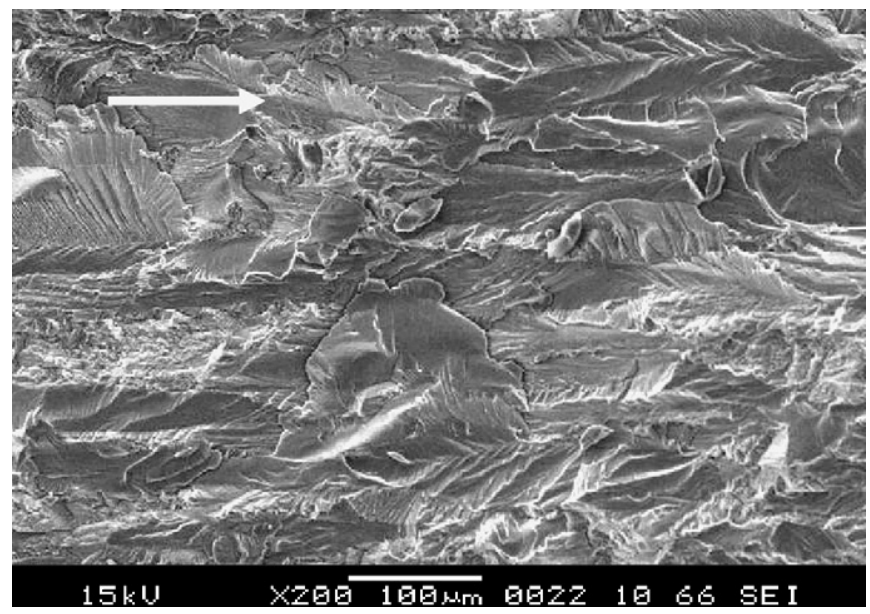

Fig. 13. SEM micrograph of the fracture surface at the near-threshold level, $7475-\mathrm{T} 7351, R=0.5,0 \%$ pre-strain, $250 \times$. Arrow indicates the direction of crack propagation. 


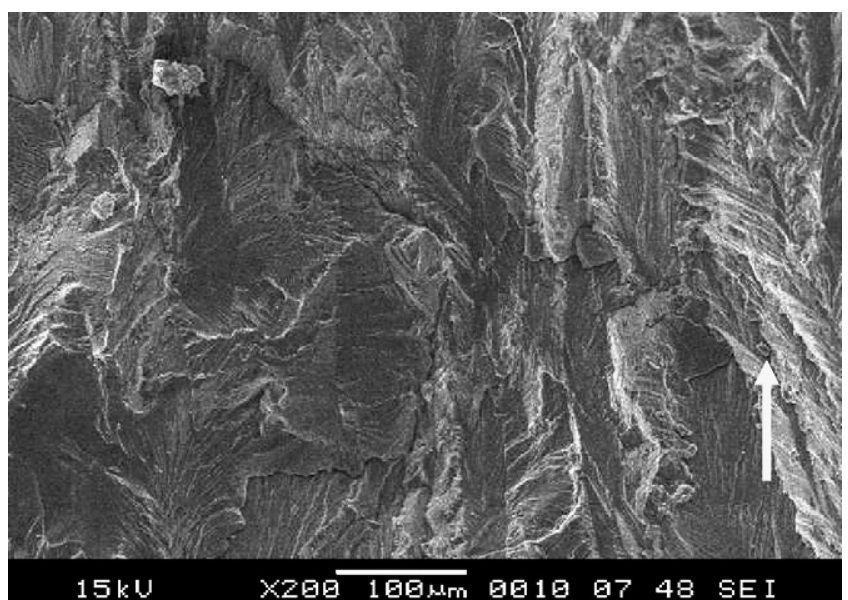

Fig. 14. SEM micrograph of the fracture surface at the near-threshold level, 7475 -T7351, $R=0.1,5 \%$ pre-strain, $200 \times$. Arrow indicates the direction of crack propagation.

of crack growth were also observed in the pre-strained specimens at both $R$ ratios.

At near-threshold level and at $R=0.5$, the SEM micrograph of fatigue fracture surface for the specimen without pre-strain is shown in Fig. 13. If Figs. 11 and 13 are compared, it is possible to conclude that higher $R$ ratio promotes a smoother fracture surface. This conclusion indicates a change in the crack closure mechanism. The same result is obtained when the effect of prestrain is considered (Fig. 14).

\section{Conclusions}

Fatigue crack growth rate in pre-strained 7475-T7351 aluminum alloy plate was evaluated in air and at room temperature under constant amplitude loading at stress ratios of 0.1 and 0.5 , using compact tension specimens. To show the effect of stress ratio $(R)$ on FCGR, Walker equivalent stress intensity factor model was used. Consequently, generalized Collipriest (GC), generalized Priddle (GP), and generalized NASGRO (GN) models were developed and fitted to the FCGR data. The generalized fitting models may be used to interpolate FCGR for $R$ ratios that were not considered in the testing program, thereby reducing both time and cost. For model validation, different commonly used graphical plots and statistical numerical measures were presented. From the results obtained, the following conclusions can be drawn:

1. The effect of pre-strain may be seen in the unstable region, region III, where the increase of pre-strain leads to decrease material fracture toughness, thereby, increasing the FCGR. The pre-strain has no considerable influence in the Paris region. In the near-threshold region, at $R=0.1, \Delta K_{\text {th }}$ decreases with an increase in pre-strain level. On the other hand, at $R=0.5$, a clear relation was not found.

2. Both generalized Collipriest and generalized Priddle models fit the FCGR data in a similar fashion. However, the latter provides a better fit than the former.
3. The generalized NASGRO (GN) model provides the best fit to the FCGR data as compared with the generalized Collipriest (GC) and generalized Priddle (GP) models. Therefore, this model may be suggested for use in critical applications, such as aeronautical structural design.

\section{References}

[1] I.J. Polmear, Light Alloys: Metallurgy of the Light Metals, second ed., Edward Arnold, 1989.

[2] H. Buhl (Ed.), Advanced Aerospace Materials, Springer, 1992.

[3] J.-P. Imarigeon, R.T. Holt, A.K. Koul, L. Zhao, W. Wallace, J.C. Beddoes, Mater. Charact. 35 (1994) 41-67.

[4] E.A. Starke Jr., J.T. Staley, Prog. Aerospace Sci. 32 (1996) 131172.

[5] J.C. Williams, E.A. Starke Jr., Acta Mater. 51 (2003) 5775-5799.

[6] W. Wallace, D.W. Hoeppner, P.V. Kandachar, Aircraft corrosion: causes and case histories, AGARD AG 278, vol. 1, 1985.

[7] G.H. Koch, Fatigue and Fracture, ASM Handbook, vol. 19, 1996, pp. 483-506.

[8] H. Vogt, M.O. Speidel, Corros. Sci. 40 (1998) 251-270.

[9] B.W. Lifka, Aluminum 53 (1977) 750-752.

[10] D.O. Sprowls, E.H. Spuhler, Avoiding Stress-corrosion Cracking in High Strength Aluminum Alloy Structures, Alcoa Green Letter, Alcoa, January 1982.

[11] S.J. Cieslak, P.L. Mehr, Alcoa 7475 Sheet and Plate, fourth revised ed., Alcoa Green Letter, 1985.

[12] A. Smolej, M. Gnamus, E. Slacek, J. Mater. Process. Technol. 118 (2001) 397-402.

[13] V.M. Radhakrishnan, P.S. Baburamani, Mater. Sci. Eng. 17 (1975) 283-288.

[14] J. Schijve, Eng. Fracture Mech. 8 (1976) 575-581.

[15] J. Wasén, B. Karlsson, Int. J. Fatigue 11 (1989) 395-405.

[16] L. Nian, D. Bai-Ping, Int. J. Fatigue 14 (1992) 41-44.

[17] ASTM E8, Annual Book of ASTM Standards, ASTM, 2001.

[18] ASTM E647, Annual Book of ASTM Standards, ASTM, 2001.

[19] ASTM E561, Annual Book of ASTM Standards, ASTM, 2001.

[20] P.K. Liaw, J.D. Landes, Fracture Mechanics, Eighteenth Symposium, vol. 945, ASTM STP, 1988, pp. 622-646.

[21] I. Bar-On, F.R. Tuler, W.M. Howerton, Nonfracture Mechanics, Vol. II-Elastic-Plastic Fracture, vol. 995, ASTM STP, 1989, pp. 244-258.

[22] W.A. Cassada, Proc. 3rd Intl. Conference Aluminum Alloys, SINTEF, vol. 1, 1992, pp. 243-248.

[23] S.D. Antolovich, Fatigue and Fracture, ASM Handbook, vol. 19, 1996, pp. 27-41.

[24] P.C. Paris, F. Erdogan, J. Basic Eng. Dec. (1963) 528-534.

[25] J.E. Collipriest, ASME (1972) 43-61.

[26] J.E. Collipriest, R.M. Ehret, C. Thatcher, NASA Technology Utilization Report, MFS-24447, 1973.

[27] T.L. Anderson, Fracture Mechanics: Fundamentals and Applications, second ed., CRC Press, 1995.

[28] R.G. Forman, S.R. Mettu, Behavior of Surface and Corner Cracks Subjected to Tensile and Bending Loads in Ti-6Al-4V Alloy, vol. 1131, ASTM STP, 1992, pp. 519-546.

[29] E.K. Walker, The Effect of Stress Ratio During Crack Propagation and Fatigue for 2024-T3 and 7075-T6 Aluminum: Effect of Environment and Complex Load History on Fatigue Life, vol. 462, ASTM STP, 1970, pp. $1-14$.

[30] M. Klesnil, P. Lukáš, Fatigue of Metallic Materials, second revised ed., Elsevier Science, 1992, p. 120.

[31] D.M. Bates, D.G. Watts, Nonlinear Regression Analysis and its Applications, John Wiley \& Sons, 1988.

[32] D.W. Marquardt, J. Soc. Ind. Appl. Math. 11 (1963) 431-441.

[33] J.M. Chambers, W.S. Cleveland, B. Kleiner, P.A. Tukey, Graphical Methods for Data Analysis, Duxbury Press, 1983.

[34] J.L. Devore, N.R. Farnum, Applied Statistics for Engineers and Scientists, Duxbury Press, 1999. 
[35] K.P. Burnham, D.R. Anderson, Model Selection and Multimodel Inference: A Practical Information-theoretic Approach, second ed., Springer, 2002.

[36] K.S. Al-Rubaie, L.B. Godefroid, J.A.M. Lopes, Int. J. Fatigue 29 (2007) 931-940.

[37] K.D. Unangst, T.T. Shih, R.P. Wei, Eng. Fracture Mech. 9 (1977) 725-734.

[38] R.D. Brown, J. Weertman, Eng. Fracture Mech. 10 (1978) 757-771.

[39] R.J. Stofanak, R.W. Hertzberg, G. Miller, R. Jaccard, K. Donald, Eng. Fracture Mech. 17 (1983) 527-539.

[40] P.K. Liaw, T.R. Leax, W.A. Logsdon, Acta Metall. 31 (1983) 1581-1587.

[41] V.B. Dutta, S. Suresh, R.O. Ritchie, Metall. Trans. 15A (1984) 1193-1207.

[42] P.E. Bretz, J.I. Petit, A.K. Vasudevan, Fatigue Crack Growth Threshold Concepts, The Metallurgical Society/AIME, 1984, pp. 163-183.

[43] A.F. Blom, Fatigue Crack Growth Threshold Concepts, The Metallurgical Society/AIME, 1984, pp. 263-279.

[44] E. Zaiken, R.O. Ritchie, Metall. Trans. 16A (1985) 1467-1477.

[45] R.O. Ritchie, W. Yu, A.F. Blom, D.K. Holm, Fatigue Fracture Eng. Mater. Struct. 10 (1987) 343-362.
[46] K. Tanaka, Mechanics and Micromechanics of Fatigue Crack Propagation, vol. 1020, ASTM STP, 1989, pp. 151-183.

[47] M.J. Couper, J.R. Griffiths, Fatigue Fracture Eng. Mater. Struct. 13 (1990) 615-624.

[48] A.J. McEvily, Fatigue and Fracture, ASM Handbook, vol. 19, 1996, pp. 134-152.

[49] S.A. Padula II., A. Shyam, R.O. Ritchie, W.W. Milligan, Int. J. Fatigue 21 (1999) 725-731.

[50] D.W. Chung, M.C. Chaturvedi, Mater. Sci. Eng. 48 (1981) 27-34.

[51] K.S. Ravishandran, H.C.V. Rao, E.S. Dwarakadasa, C.G.K. Nair, Metall. Trans. 18A (1987) 865-876.

[52] S.K. Putatunda, Eng. Fracture Mech. 30 (1988) 627-639.

[53] K. Nakajima, S. Kamiishi, M. Yokoe, T. Miyata, The Influence of Microstructural Morphology and Prestrain on Fatigue Crack Propagation of Dual-phase Steels in the Near-threshold Region, vol. 39, ISIJ International, 1999, pp. 486-492. 